\title{
Changes in waveform of congenital nystagmus associated with biofeedback treatment
}

\author{
Mikako Mezawa, Satoshi Ishikawa, Kazuhiko Ukai
}

\begin{abstract}
A study was made of the parameters of congenital nystagmus which responded to auditory biofeedback treatment. The parameters studied included foveation time, amplitude, and frequency. The patient's right retina was observed with an infrared television fundus camera, and the fundus image was recorded on video tape. The position of the eye during nystagmus, observed via the fundus camera and recorded on video, was analysed at every 1/60 second intervals. The displacement in degrees between the fixation target, projected on to the retina, and the foveola was measured for each interval. Using biofeedback, the subjects could voluntarily suppress nystagmus and prolong foveation time. A damping of the nystagmus amplitude, intensity, and frequency was observed. On the average the intensity decreased by about $40 \%$, and the foveation time was prolonged by about $190 \%$. After completion of the training all the patients reported a subjective improvement in their vision when suppressing their nystagmus. Possibly biofeedback training acts to reduce the nystagmus and extend foveation time, thereby improving the ability to fixate.
\end{abstract}

Non-surgical treatment of congenital nystagmus has included prism treatment ${ }^{1}$ as well as drug treatment. ${ }^{23}$ Recently an auditory biofeedback method, as well as acupuncture, was introduced..$^{47}$ Well trained patients can damp their nystagmus by using acoustic signals generated from the eye movements. Following training some patients could deliberately suppress their nystagmus even without the use of auditory equipment. However, the reason for the effective damping of nystagmus by this method remains unclear. To understand this effect better it is important to compare waveform and foveation time before and after suppression of nystagmus.

Classifications of congenital nystagmus wave-
Table 1 Status summary for each patient

\begin{tabular}{|c|c|c|c|c|c|c|c|}
\hline \multirow[b]{2}{*}{ Case } & \multirow[b]{2}{*}{ Age } & \multirow[b]{2}{*}{ Sex } & \multicolumn{2}{|c|}{ Corrected vision } & \multirow{2}{*}{$\begin{array}{l}\text { Null point } \\
\text { location } \\
\text { (degrees) }\end{array}$} & \multirow{2}{*}{$\begin{array}{l}\text { Waveform prior to } \\
\text { voluntary suppression }\end{array}$} & \multirow{2}{*}{$\begin{array}{l}\text { Result of } \\
\text { voluntary } \\
\text { suppression }\end{array}$} \\
\hline & & & Right & Left & & & \\
\hline $\begin{array}{l}1 \\
2 \\
3 \\
4 \\
5\end{array}$ & $\begin{array}{l}20 \\
17 \\
18 \\
13 \\
13\end{array}$ & $\begin{array}{l}\mathbf{F} \\
\mathbf{F} \\
\mathbf{M} \\
\mathrm{F} \\
\mathbf{M}\end{array}$ & $\begin{array}{l}20 / 20 \\
20 / 20 \\
20 / 20 \\
20 / 40 \\
20 / 30\end{array}$ & $\begin{array}{l}20 / 20 \\
20 / 20 \\
20 / 20 \\
20 / 30 \\
20 / 30\end{array}$ & $\begin{array}{lr} & 0 \\
\text { Left } & 5 \\
0 \\
\text { Left } 10 \\
\text { Left } 10\end{array}$ & $\begin{array}{l}\text { Jerk with extended foveation } \\
\text { Dual jerk } \\
\text { Jerk with extended foveation } \\
\text { Pure jerk } \\
\text { Pseudopendular with } \\
\text { saccades }\end{array}$ & $\begin{array}{l}\text { Excellent } \\
\text { Excellent } \\
\text { Excellent } \\
\text { Fair } \\
\text { Excellent }\end{array}$ \\
\hline 6 & 17 & $M$ & $20 / 50$ & $20 / 70$ & 0 & $\begin{array}{l}\text { Pendular with foveating } \\
\text { saccades }\end{array}$ & Fair \\
\hline 7 & 7 & M & $20 / 100$ & $20 / 100$ & 0 & $\begin{array}{l}\text { Pendular with foveating } \\
\text { saccades }\end{array}$ & Poor \\
\hline
\end{tabular}

forms have been studied. ${ }^{89}$ However, the change in waveform by biofeedback training has not been studied. Direct observation of the fovea is absolutely essential to analysing these changes, especially changes in the foveation time. To accomplish this we used an infrared television camera with a built-in fixation target. Time sequence fundus photography was performed every $1 / 60$ second $(16.7 \mathrm{~ms})$ and was analysed by an image analyser tied into a computer system. In particular the relationship between the position of the foveola and the projected fixation target on the retina was measured. Changes in the foveation time as well as in the waveform were thus demonstrated.

\section{Materials and methods}

\section{PATIENTS}

Seven patients between the ages of 7 and 20 (mean 15) were studied. All had horizontal congenital nystagmus. Table I summarises the status of the patients and the results of biofeedback therapy. Four cases (nos 1, 2, 3, 4) were of the jerk type while the others (nos $5,6,7$ ) were either pendular or pseudopendular types of nystagmus. Apart from nystagmus no other ocular anomaly was present. We have also examined for and excluded the presence of albinism or partial variants of it and of optic nerve hypoplasia. In cases $1,3,6$, and 7 the null point was located in the primary position, while in cases 2,4 , and 5 the null points were located to the left $5^{\circ}, 10^{\circ}$, and $10^{\circ}$ respectively. Each patient participated in auditory biofeedback therapy for the suppression of the nystagmus five or six times over a six-month period. This method has been mentioned elsewhere. ${ }^{6}$ Convergence training was used with an associated increase in the tonus of frortal, orbicular, abdominal, diaphragmatic, or throat muscles.

During the biofeedback treatment eye movements were recorded by a limbus tracking device (photoelectric oculography with a bandwidth of $100 \mathrm{~Hz}$ ). After being trained most patients could control their nystagmus partly and in some cases completely, even without the auditory feedback equipment. In cases $1,2,5$, and 7 the damping of nystagmus was associated with changes in lid muscle tonicity, while cases 3,4 , and 6 associated a damped nystagmus with changes in tonicity of the diaphragm and abdominal muscles.

OBSERVATION OF NYSTAGMUS FROM THE FUNDUS

The retina was observed with an infrared television fundus camera with and without voluntary suppression. Its assembly and this method have 


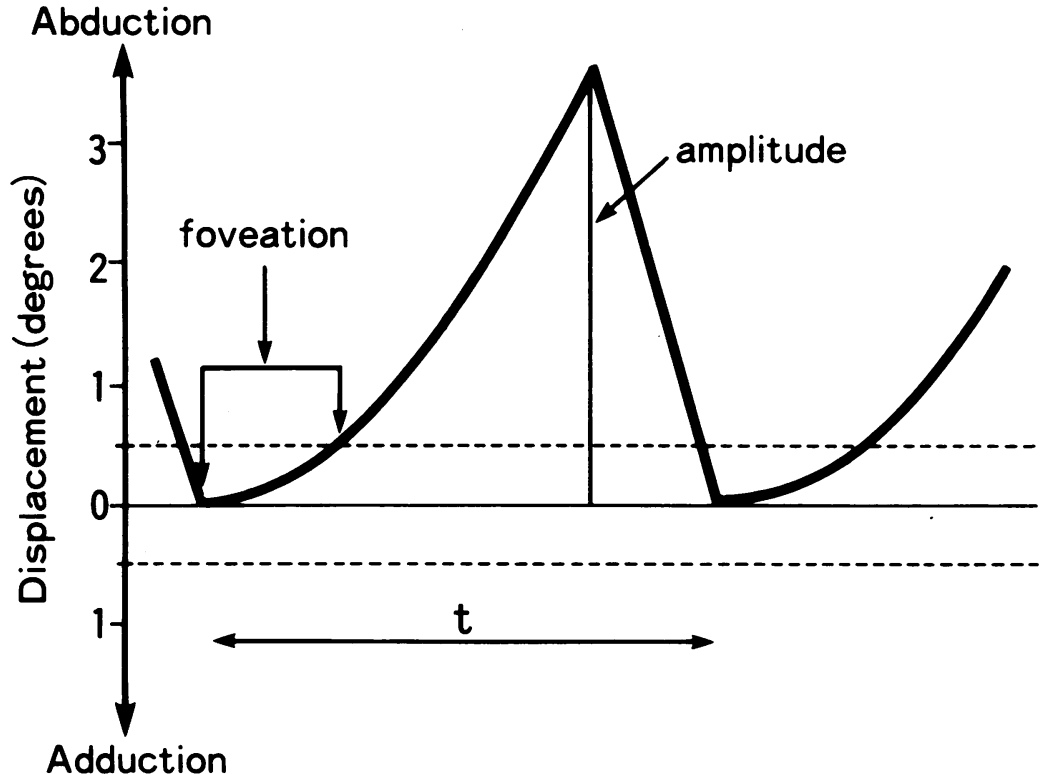

Adduction
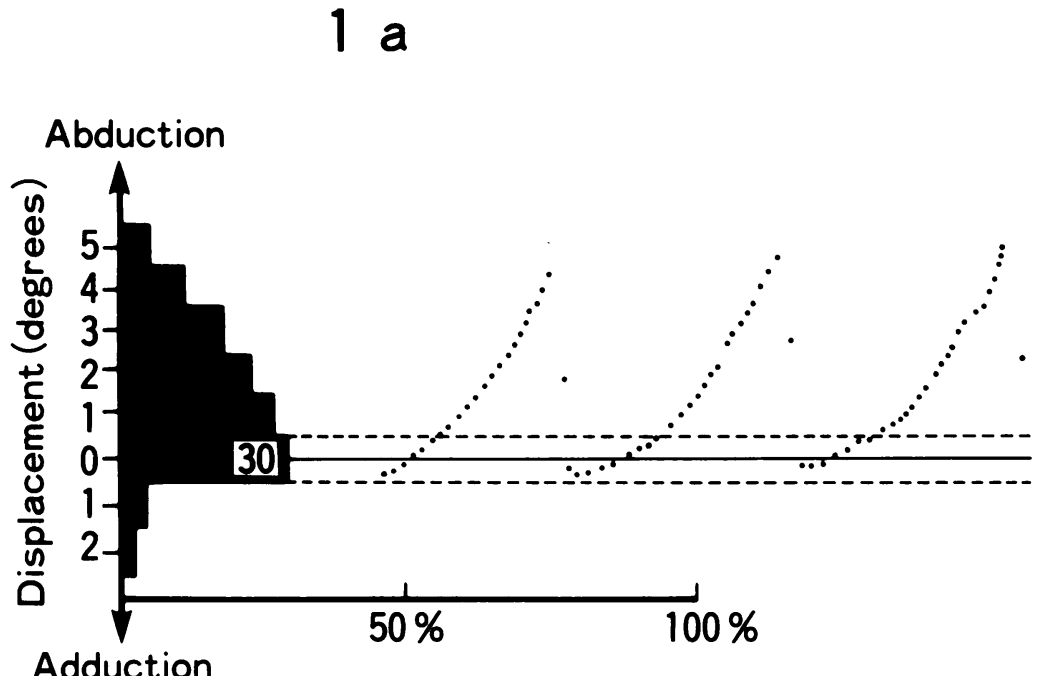

Histogram in \%

$1 \mathrm{~b}$

Figure 1. Waveform analysis (schematic drawing). a: Determination of foveation indicated by two vertical arrows. Amplitude and frequency $(1 / t)$ are measured as shown. The zero axis indicates the foveola with a dotted line $0.5^{\circ}$ to either horizontal directions defining the central foveal zone. b: Actual plot of a nystagmus waveform. Only the first three waves are shown. Each dot in the waveform corresponds to a $1 / 60$ second video picture. The number of dots within each one degree zone surrounding the central foveal zone was tallied and plotted in the histogram to the left. The number 30 at the centre of the histogram indicates the maximum dot density within a $1^{\circ}$ zone as a percentage of total.

been described previously by Tani. ${ }^{10}$ The patient was asked to fixate a target of $2^{\prime}$ in visual angle which was set inside the infrared television fundus camera. The right eye was used in all cases. The image of the fundus and the position of the fixation target over time were recorded by the videotape recorder. The position of two specific retinal points, such as the crossing of two vessels or a vessel crossing the disc margin, was measured in each $1 / 60$ second time sequence picture over a 10 second period for each case. We thus obtained a total of 600 points of postion data from the fundus picture recordings of each eye, which were then converted into nystagmus waveforms to show the position of the foveola with regard to the fixation target over time. The average error as indicated by standard deviation was less than $3^{\prime}$ of arc. Using this method and by analysing each waveform in this way, we could establish the status of foveal fixation in each case.

\section{ANALYSIS}

For each case the nystagmus was classified according to the waveform obtained by the above method. We also analysed amplitude, frequency, intensity (amplitude $\times$ frequency), and foveation time. In addition the analysis of eye positions expressed as a percentage rate was shown by histogram. For the purposes of analysis the fixation target was considered to be at the zero point, and the ordinates indicate the eye position. As shown in Figure la, a zone of $0.5^{\circ}$ (temporal and nasal) from the target was chosen as the central zone for foveal fixation. Foveation time is taken as the amount of time spent by the eye position within this zone and is indicated in this example by the horizontal distance between the two arrows. Note that the wave portion where the eye crossed into the central zone, corresponding to the quick phase of nystagmus, was not included in the calculation of foveation time. Foveation time was recorded in milliseconds. A histogram was made showing the breakdown of time spent by the eye (that is the number of dots) as a percentage rate, in the central foveal zone as well as for other $1^{\circ}$ zones extending nasally and temporally out from the fovea. In the example in Figure $1 \mathrm{~b}$, as well as in most of the cases, the maximum percentage on the histogram corresponds with central fixation. The number above the histogram peak indicates this percentage rate.

\section{Results}

\section{CHANGE IN WAVEFORM WITH VOLUNTARY} SUPPRESSION

The waveforms (Fig 2) and the histograms (Fig 3) obtained from the seven cases are shown. Case 1 had leftward jerk nystagmus with extended foveation. Without voluntary suppression (A) the eye moved away from the target during the slow phase, and foveation, indicated by arrows, occurred at the termination of the quick phase. With voluntary suppression (B) nystagmus was reduced and excellent foveation was seen. In Figure 3 the histogram shows that the central foveal zone has the largest percentage of time, improving significantly from $32 \%$ to $76 \%$ with voluntary suppression.

Case 2 had a rightward jerky nystagmus. Without voluntary suppression the eye moved away from the foveola during the fast phase, and foveation occurred during the slow eye movements. With voluntary suppression excellent foveation was seen with some small occasional flicks, possibly a physiological form of nystagmus. The histogram maximum percentage significantly improved from $36 \%$ to $82 \%$ with voluntary suppression.

Case 3 had leftward jerk nystagmus with extended foveation. The foveation is shown by arrows and the waveform changed from a unidirectional type to a bidirectional type jerk nystagmus with voluntary suppression. The his- 
A

B

Case 1
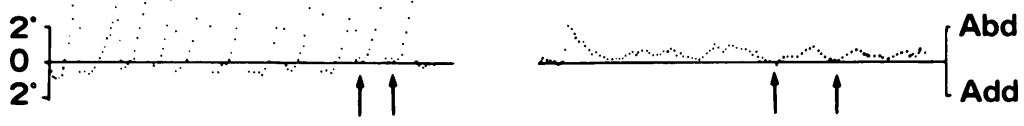

Case 2
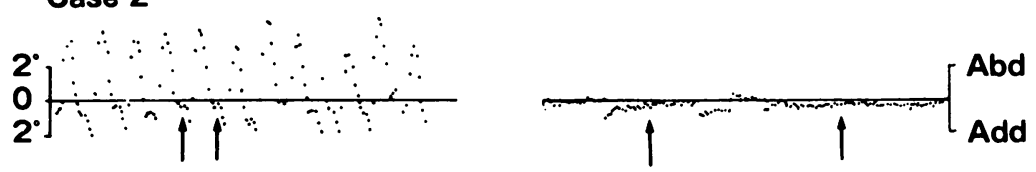

Case 3
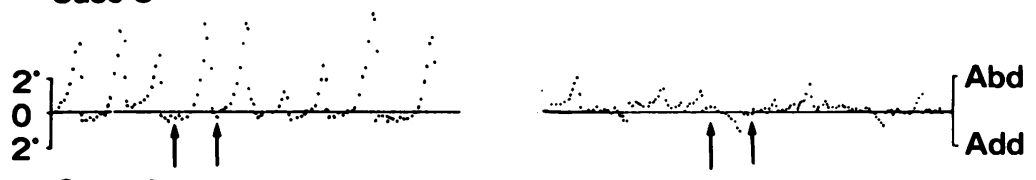

Case 4
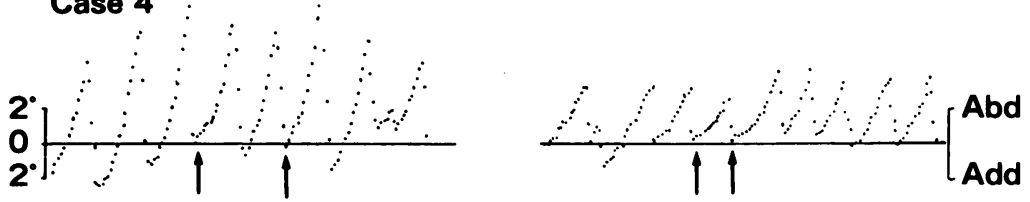

Case 5
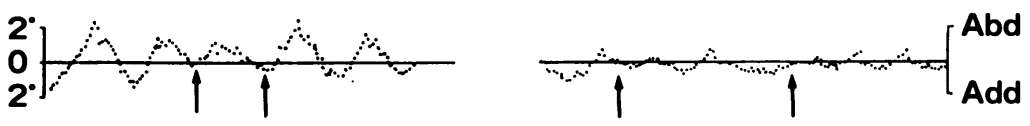

\section{Case 6}
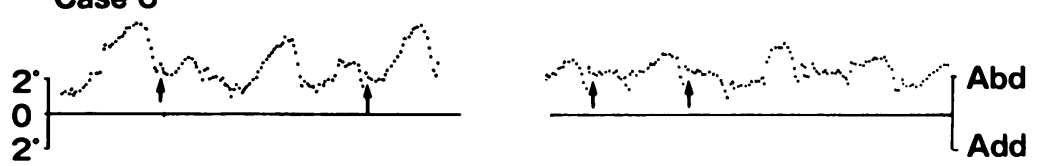

Case 7
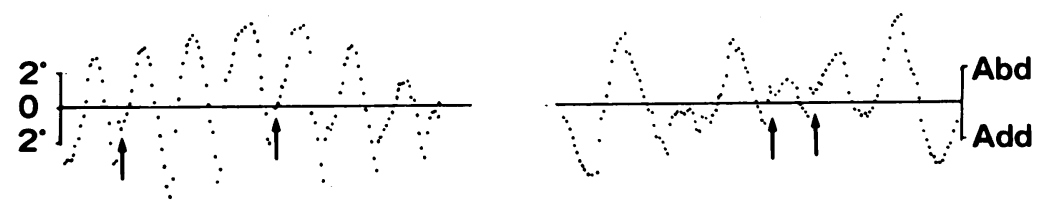

$1 \mathrm{sec}$

Figure 2 Waveforms for all cases prior to $(A)$ and with $(B)$ voluntary suppression are shown. Cases 1, 2, 3, and 4 are jerky, while case 5 is pseudopendular with foveating saccades, and cases 6 and 7 are pendular. Foveation is shown by small arrows. Excellent suppression can be seen in cases $1,2,3$, and 5 .
In case 6 we observed a pendular nystagmus with foveating saccades. Notice that the entire waveform is shifted approximately $2^{\circ}$ to the nasal side of the foveola. With voluntary suppression the amplitude dropped, but the eccentric fixation did not change. The maximum rate in the histogram shifted from $28 \%$ to $53 \%$.

Case 7 also had a pendular nystagmus with foveating saccades. Since the foveating saccade passed through the foveola, the foveation time was extremely short. With voluntary suppression there was a reduction in frequency but the amplitude remained unchanged. The maximum rate in the histogram changed from $19 \%$ to $20 \%$.

\section{CHANGE IN PARAMETERS WITH VOLUNTARY} SUPPRESSION

In all cases presented here the parameters of nystagmus - namely, the amplitude, frequency, intensity, and the foveation time - improved with voluntary suppression. Average data for each parameter is shown in Table II. All cases showed a reduction in amplitude. Frequency dropped in five cases, and increased slightly in the pseudopendular (no 5) and pendular (no 6) nystagmus cases. Foveation time was prolonged in all cases. Histogram maximum values also improved in all cases. The right-hand colum summarises the waveform changes observed.

Subjects with good visual acuity (nos 1,2 , and 3) had a foveation time of over $300 \mathrm{~ms}$ out of each second prior to biofeedback treatment. With biofeedback-induced voluntary suppression this value improved to over $700 \mathrm{~ms}$. Clearly voluntary suppression was effective in prolonging the foveation time.

\section{Discussion}

The infrared fundus television camera can cover an area of about $20^{\circ}$ horizontally and vertically, so we have selected patients with a null point in the primary position or close to the primary position. By limiting subjects in this way one can obtain a precise picture for analysis of the nystagmus. This is the best method available for direct observation of foveation.

The jerky type of congenital nystagmus foveates at the termination of the quick phase. However, in case 2 the foveation occurred during the slow phase of nystagmus as shown by the arrows. This type of waveform, in which foveation did not exist immediately after the quick phase, was not included in Dell'Osso's classification of congenital nystagmus. Recently we observed another case which was quite similar to it. As seen from commercial electric nystagmography recordings, this should be classified as a dual jerk nystagmus. It is interesting to note that foveation is being made during the slow phase. These findings suggest that dual jerk nystagmus may require classification into two subcategories - one in which the foveation is performed by saccade and another in which foveation is made during the slow phase. An almost similar case has been recorded recently by Bedell et al."

The nystagmus of case 3 was classified as jerk with extended foveation prior to voluntary sup- foveating saccades. The amplitude of the nystagmus was not large. With voluntary suppression foveation increased and the amplitude decreased. The histogram maximum increased from $46 \%$ to $69 \%$. 

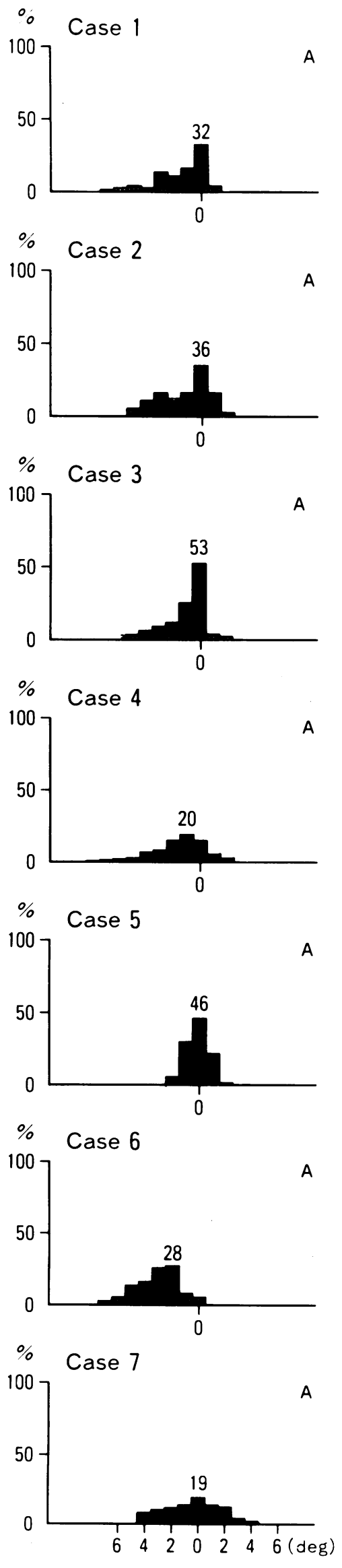

Abduction (Abd) Adduction (Add)
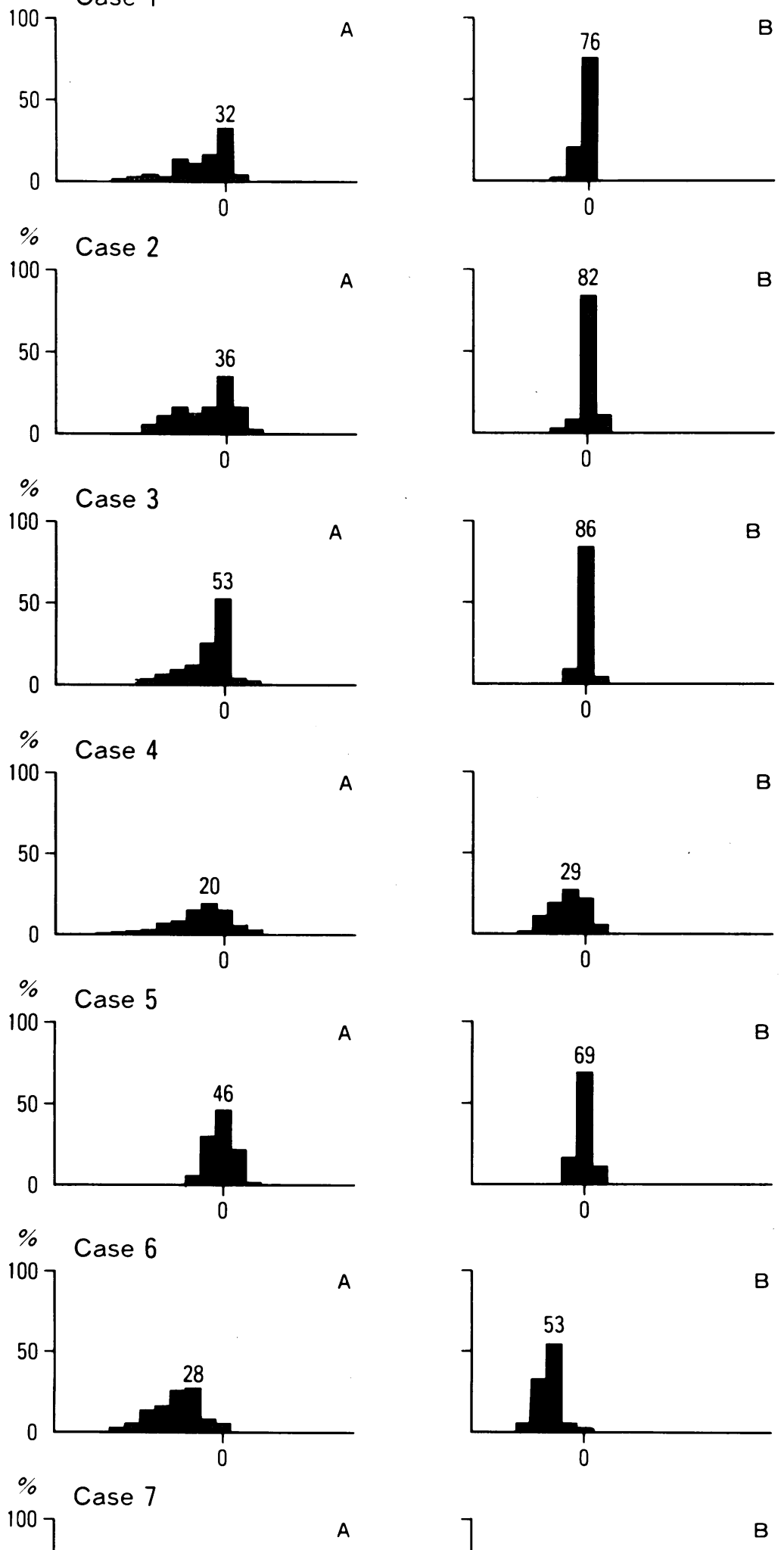

Figure 3 The position of the target in relation to the foveola. The ordinate of the histogram shows the frequency distribution as a percentage. The abscissa indicates the position of the target in relation to the foveola prior to voluntary suppression $(A)$ and with voluntary suppression $(B)$. Numbers above the histogram peaks indicate the maximum dot density in percentages: that means location of the eye within the central or, in cases 4 and 6 , eccentric zone. pression. With voluntary suppression the nystagmus changed to both jerk with extended foveation and frequent bias (direction) shifts and to a bidirectional jerk type. Dell'Osso ${ }^{12}$ reported that $87 \%$ of congenital nystagmus cases had multiple waveforms in any given patient. The change of waveform is induced by changes in the angle of gaze, emotional state, visual stimulation, fixation effort, etc. We found that, in electric nystagmography recordings in case 3 , the bidirectional jerk waveform was not present in any angle of gaze prior to voluntary suppression, but with voluntary suppression the bidirectional jerk appeared. This suggested that the waveform change induced by voluntary suppression may involve a different mechanism from that used when the nystagmus waveform changes with angle of gaze.

On the other hand the nystagmus waveform in cases 4 to 7 did not alter with voluntary suppression. These cases showed only a change in amplitude. Foveation in case 4 was made at the termination of the quick phase, and this remained the same with voluntary suppression, though amplitude was reduced. According to Dell'Osso's report ${ }^{12}$ subjects with pendular nystagmus with foveating saccades usually have multiple waveforms, such as jerk with extended foveation or pseudocycloid and pendular. In cases 5 and 6 there was a reduction in amplitude with voluntary suppression, while the frequency did not reduce. A slight increase in foveation was seen, and the precision of the foveation improved, with the disappearance of the overshoot and undershoot saccades which existed prior to suppression in cases 6 and 7 . These results are summarised as an extension of the foveating time, and it was best demonstrated in the histogram analysis. We have seen that prolongation of foveation with biofeedback training is more effective in jerk than in pendular nystagmus.

The exact mechanism of voluntary suppression of nystagmus by means of an auditory cue remains unclear. Increasing muscle tension in the lids as well as changes in the tonicity of the laryngeal or pharyngeal muscles may modulate the intensity of the nystagmus amplitude. Embryologically the trigeminal, facial, glossopharyngeal, vagus, and recurrent laryngeal nerves all develop from the same branchiogenic nerve. Biofeedback training possibly makes use of these common pathways, which may still exist after birth.

As to visual acuity, several studies have shown little improvement in visual acuity despite an improvement in the nystagmus. ${ }^{5}$ We have previously reported that contrast sensitivity was improved by only $0 \cdot 1-0 \cdot 2 \log$ unit over a wide range of spatial frequencies. ${ }^{13}$ A similar result was seen with prism training, ${ }^{14}$ in which the induced convergence triggered suppression but caused a decrease in contrast sensitivity ${ }^{13}$ due to convergence-induced overaccommodation.

In some cases we have seen an improvement in the rate of central zone foveal fixation with no change in waveform. Furthermore, visual input plays an important part in maintaining centric fixation during foveation, so the waveform changes and reduction in the amplitude during 
Table 2 Comparison of parameters prior to and with voluntary suppression (average values)

\begin{tabular}{|c|c|c|c|c|c|c|c|c|c|c|c|}
\hline \multirow[b]{2}{*}{ Case } & \multicolumn{2}{|c|}{$\begin{array}{l}\text { Amplitude } \\
\text { (deg) }\end{array}$} & \multicolumn{2}{|c|}{$\begin{array}{l}\text { Frequency } \\
(\mathrm{Hz})\end{array}$} & \multicolumn{2}{|c|}{$\begin{array}{l}\text { Intensity } \\
(\text { deg } \times H z)\end{array}$} & \multicolumn{2}{|c|}{$\begin{array}{l}\text { Foveation } \\
\text { time } \\
\text { (ms) }\end{array}$} & \multicolumn{2}{|c|}{$\begin{array}{l}\text { Maximum } \\
\text { histogram } \\
\text { rate }(\%)\end{array}$} & \multirow[b]{2}{*}{ Change in waveform } \\
\hline & $A$ & $B$ & $A$ & $B$ & $A$ & $B$ & $A$ & $B$ & $A$ & $B$ & \\
\hline $\begin{array}{l}1 \\
2 \\
3 \\
4 \\
5 \\
6 \\
7\end{array}$ & $\begin{array}{l}7 \cdot 2 \\
4 \cdot 5 \\
2 \cdot 8 \\
5 \cdot 5 \\
2 \cdot 4 \\
3 \cdot 1 \\
6 \cdot 1\end{array}$ & $\begin{array}{l}3 \cdot 1 \\
2.3 \\
2.0 \\
3.1 \\
1.3 \\
1.9 \\
5 \cdot 3\end{array}$ & $\begin{array}{l}4.4 \\
4.5 \\
3.8 \\
3.7 \\
1.8 \\
2.3 \\
3.1\end{array}$ & $\begin{array}{l}1.2 \\
0.3 \\
1.8 \\
3.3 \\
2.1 \\
2.7 \\
2.3\end{array}$ & $\begin{array}{r}31.7 \\
20.3 \\
10.7 \\
20.4 \\
4.3 \\
7.1 \\
18.9\end{array}$ & $\begin{array}{r}3.7 \\
0.7 \\
3.6 \\
10.2 \\
2.6 \\
5.1 \\
12.2\end{array}$ & $\begin{array}{l}374 \\
344 \\
573 \\
200 \\
204 \\
254 \\
133\end{array}$ & $\begin{array}{l}767 \\
912 \\
864 \\
304 \\
538 \\
349 \\
193\end{array}$ & $\begin{array}{l}32 \\
36 \\
53 \\
20 \\
46 \\
28 \\
19\end{array}$ & $\begin{array}{l}76 \\
82 \\
86 \\
29 \\
69 \\
53 \\
20\end{array}$ & $\begin{array}{l}\text { Almost normalised } \\
\text { Normalised } \\
\text { Bias shifts and bidirectional jerk } \\
\text { Jerk (no change) } \\
\text { Pseudopendular (no change) } \\
\text { Pendular with foveating saccades (no change) } \\
\text { Pendular with foveating saccades (no change) }\end{array}$ \\
\hline
\end{tabular}

A: prior to voluntary suppression. B: with voluntary suppression.

self control may be attributed to improvement in some visual function such as visual attention or deliberate viewing.

The authors express their thanks to Dr Louis Dell'Osso for his kind help in establishing the work. This work was in part supported by the grant no $01870075(1990)$ from the Ministry of Education in Japan.

1 Bagolini B. Orthoptic and prismatic treatment of congenital nystagmus. In: Reinecke, ed. Strabismus. New York: Grune nystagmus. In: Reinecke, ed.
and Stratton, 1978: 191-201.

2 Larmande P, Pautrizel B. Traitement du nystagmus congénital par le 5-hydroxytryptopane. Nouv Presse Med 1981; 10: 3166

3 Yee RD, Baloh RW, Honrubia V. Effect of baclofen on congenital nystagmus. In: Lennerstrand $G$, et al, eds. Functional basis of ocular motility disorders. Elmsford, NY: Pergamon, 1982: 151-7.

4 Abadi RV, Carden D, Simpson J. A new treatment for congenital nystagmus. Br $\mathcal{F}$ Ophthalmol $1980 ; 64: 2-6$.

5 Ciuffreda KJ, Goldrich SG, Neary C. Use of eye movement auditory biofeedback in the control of nystagmus. Am f Optom Physiol Opt 1982; 59: 396-409.
6 Ishikawa S, Tanakadate A, Nabatame K, Ishii M. Biofeedback treatment of congenital nystagmus. Neuro-ophthalmology fpn 1985; 2: 58-64.

7 Ishikawa S, Ozawa $\mathbf{H}$, Fujiyama $Y$. Treatment of nystagmus by acupuncture. In: Ishikawa S, ed. Highlights in neuroophthalmology. Amsterdam: Aeolus, 1987: 227-32.

8 Dell'Osso LF, Daroff RB. Congenital nystagmus waveform and foveation strategy. Doc Ophthalmol 1975; 39: 155-82.

9 Yee RD, Wong EK, Baloh RW, Honrubia V. A study of congenital nystagmus: waveforms. Neurology 1976; 26: $326-33$.

10 Tani I. Study on congenital nystagmus. A new method of analysis of congenital nystagmus by infrared television analysis of congenital nystagmus by infrared television fundus

11 Bedell HE, White JM, Abplanalp PL. Variability of foveations in congenital nystagmus. Clin Vis Sci 1989; 4: 247-52.

12 Dell'Osso LF. Congenital, latent and manifest latent nystagmus - similarities, differences and relation to strabismus. fpn f Ophthalmol 1985; 29: 351-68.

13 Matsubara $K$, Ukai $K$, Ito $M$, Ishikawa $S$. Concurrent measurements of congenital nystagmus intensity and contrast sensitivity with respect to voluntary suppression of nystagmus. Fpn Rev Clin Ophthalmol 1988; 82: 310-3.

14 Dickinson CM. The elucidation and use of the effect of near fixation in congenital nystagmus. Ophthalmic Physiol Opt 1986; 6: 303-11. 